\title{
Strain energy density criterion as failure assessment for quasi-static uni-axial tensile load
}

\author{
Andrea Kusch, Simone Salamina, Daniele Crivelli \\ University of Applied Sciences and Arts of Southern Switzerland, Lugano, Switzerland \\ andrea.kusch@student.supsi.ch,simone.salamina@supsi.ch, daniele.crivelli@supsi.ch
}

\author{
Filippo Berto \\ Norwegian University of Science and Technology, Norway \\ filippo.berto@ntnu.no
}

\begin{abstract}
Strain energy density is successfully used as criterion for failure assessment of brittle and quasi-brittle material behavior. This work investigates the possibility to use this method to predict the strength of Vnotched specimens made of PMMA under static uniaxial tensile load.

Samples are characterized by a variability of notch root radii and notch opening angles. Notched specimens fail with a quasi-brittle behavior, albeit PMMA has a nonlinear stress strain curve at room temperature. The notch root radius has most influence on the strength of the specimen, whereas the angle is less relevant.

The value of the strain energy density is computed by means of finite element analysis, the material is considered as linear elastic. Failure predictions, based on the critical value of the strain energy density in a well-defined volume surrounding the notch tip, show very good agreement (error $<15 \%)$ with experimental data.
\end{abstract}

KEYWORDS. Strain energy density; Quasi-brittle material; PMMA; Failure assessment.

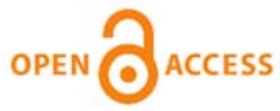

Citation: Kusch, A., Salamina, S., Crivelli, D., Berto. F., Strain energy density criterion as failure assessment for quasi-static uni-axial tensile load, Frattura ed Integrità Strutturale, 57 (2021) 331-349.

Received: 17.05 .2021

Accepted: 16.06 .2021

Published: 01.07.2021

Copyright: (C) 2021 This is an open access article under the terms of the CC-BY 4.0, which permits unrestricted use, distribution, and reproduction in any medium, provided the original author and source are credited.

\section{INTRODUCTION}

$\mathrm{R}$ eal life application components are often characterized by shapes which produce a stress concentration, that are frequently in the form of notches, holes and re-entrant corners. These weak points act as crack starter, leading to usually brittle failures for both static and fatigue loads. Traditionally, to predict the failure of weakened components, generalized stress intensify factors are used, which are difficult to obtain and depend on the weakening feature. To assess the strength of notched components it is useful to have a parameter which depends not on geometry, but rather on the material, and also to make use of numerical methods which can provide reliable results in a convenient time.

There are three fundamental ways in which a load enables the crack to propagate, called mode I, II and III. Real components are often subjected to mixed mode loading, but mode I has most practical interest because it is predominant [1]. 
Strain Energy Density

Strain energy is the energy stored in a component undergoing deformation, both elastic and plastic. It can be computed as:

$$
W=\frac{1}{2} \int_{V} \sigma \varepsilon d V
$$

Strain energy density (SED) is the average strain energy evaluated over a defined volume:

$$
\bar{W}=\frac{W}{V}
$$

For perfectly linear elastic brittle materials:

$$
\bar{W}=\int \sigma d \varepsilon=\frac{\sigma^{2}}{2 E}
$$

Finite element analysis is the tool used to numerically compute the SED in the present work. The total strain energy in a finite element is directly computed from the nodal displacement [2]:

$$
W=\frac{1}{2} \underline{\mathbf{d}}^{T} K \underline{\mathbf{d}}
$$

where:

- $\quad \underline{\mathbf{d}}$ is the vector of nodal displacements;

- $K$ is the stiffness matrix.

The same is obviously true for the strain energy density, which is computed by the strain energy divided by the volume.

\section{LITERATURE REVIEW}

1

he average strain energy density failure criterion was firstly introduced by Lazzarin and Zambardi $[3,4]$ and it is validated as failure criterion for brittle and quasi-brittle behavior [5]. Failure occurs if the average value of strain energy density, computed over a defined control volume surrounding the point of singularity, exceeds the critical value. For ideally brittle materials, the critical value of the strain energy density can be easily determined by Eqn. 3:

$$
\bar{W}_{c}=\frac{\sigma_{u t}^{2}}{2 E}
$$

The biggest advantage is that this method does not require very fine mesh for finite elements analysis, contrary to other failure assessment methods [2], because the elastic strain energy can directly be determined by nodal displacement (eq. 4), whereas stress and strain are computed with derivatives of the displacement. This property allows to get sufficiently accurate results with coarse mesh finite elements analysis, which can be solved in much less time. For this reason, it is considered a powerful tool to assess failure of notched and welded components $[6,7]$.

SED approach has been widely tested on brittle and quasi-brittle behavior, on both static and fatigue failures [8] both in simple and mixed mode loading $[9,10,11,12]$. This should cover the majority of applications, because both fatigue and the presence of a notch in ductile materials frequently induce a brittle behavior [13].

The SED approach has been proposed also as an alternative method to determine notch stress intensify factors (NSIFs) with relatively coarse meshes using simple closed form expressions [6, 2]. 

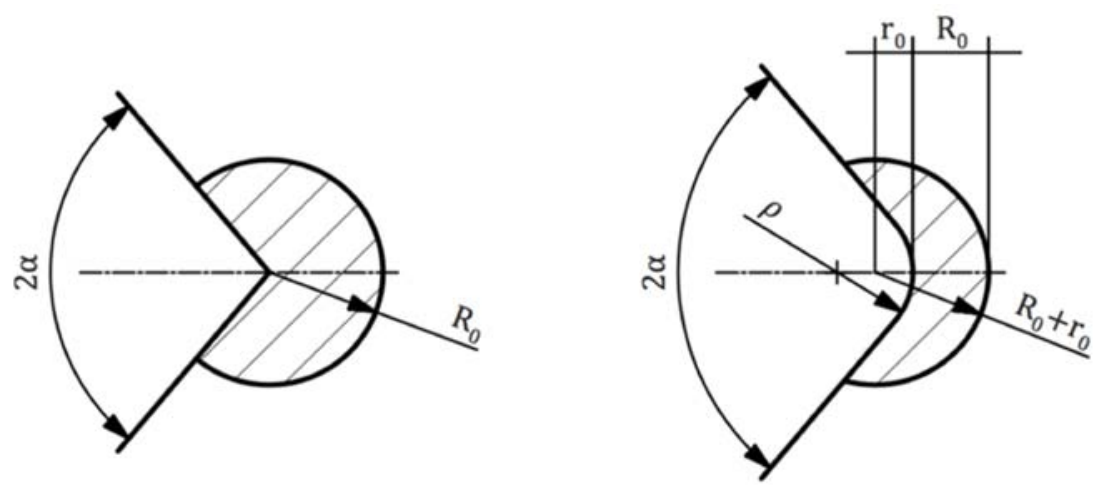

Figure 1: Control volume geometry for sharp and blunt V-notches.

Planar problems can be treated as two-dimensional, where the control volume assumes the shape of a circular segment. The center of the control volume corresponds to the edge of the notch for sharp V-notches, and is shifted towards the center of the notch root radius for blunt V-notches, as shown in Fig. 1 . In the latter case, the control radius $R_{0}$ is the width of the volume measured along the notch bisector line. For mode I loading, control radius can be evaluated for plane strain condition with the formula from [14]:

$$
R_{0, p n}=\frac{(5-8 v)(1+v)}{4 \pi}\left(\frac{K_{I C}}{\sigma_{u t}}\right)^{2}
$$

and for plane stress [15]:

$$
\mathrm{R}_{0, p s}=\frac{(5-3 v)}{4 \pi}\left(\frac{K_{I C}}{\sigma_{u t}}\right)^{2}
$$

The distance of the center of the control volume, according to Fig. 1 is defined as [16]:

$$
r_{0}=\rho \cdot \frac{\pi-2 \alpha}{2 \pi-2 \alpha}
$$

This distance is then dependent on both the notch root radius and the opening angle, decreasing with increasing angles.

\section{METHODS}

he present work follows an experimental approach to analyze the problem. In practice, what has been found in previous studies is being applied to a new set of data to validate the SED approach in static uniaxial load case, and to investigate the possibility to extend the presented failure assessment to nonlinear elastic materials.

Poly(methyl methacrylate) (PMMA) plane dog bone specimens are subjected to static tensile test to characterize the properties of the material, in particular its elastic modulus $E$ and its ultimate tensile strength $\sigma_{u t}$. Then, plane specimens weakened by a double symmetric V-notch are subjected to static tensile test to measure the force needed to break them. This value of force is then applied to a finite element model of the corresponding specimen. After finite element analysis is performed, the strain energy density is valuated over a range of control volumes, which depend on the control radius $R_{0}$. The values are compared to find the critical value of the strain energy density and the control radius $R_{0}$ for which this critical value is reached inside the control volume. Both plane strain and plane stress condition are considered and the respective results are used to evaluate which approach fits best. A validation set of notched specimens is then considered to blindly predict the failure loads using this information. 


\section{Specimen Geometry}

Control group (i.e. unnotched straight specimens) geometry is derived from ISO 527 [17]. Three different notch opening angles are considered $\left(2 \alpha=45^{\circ}, 60^{\circ}, 90^{\circ}\right)$ and two different notch root radii $\rho=1$ and $0 \mathrm{~mm}$ (the minimal radius achievable with the capability of the manufacturing process).
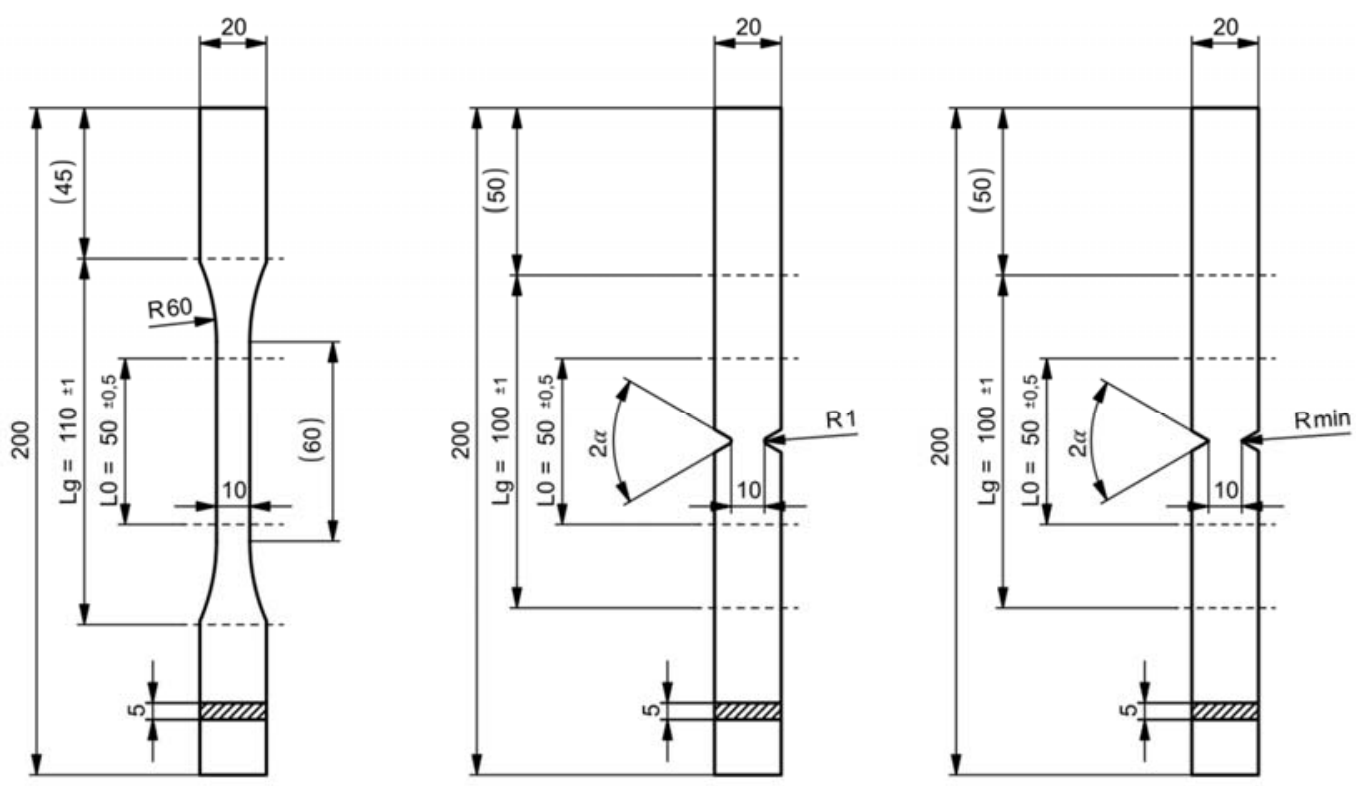

Figure 2: Specimens geometry $\left(2 \alpha .=45^{\circ}, 60^{\circ}, 90^{\circ}\right)$.

Series of specimens are labeled according to the opening angle and radius: V45R0, V60R0, V90R0, V45R1, V60R1, V90R1 and STR being the unnotched set. For each series 5 specimens are produced. Manufacturing tolerances are checked using measurements from a Leica DM ML (Leica Camera AG, Wetzlar, DE) optical microscope image data.

Three other types of blunt notched specimen are considered as validation set, with $2 \alpha=90^{\circ}$ and $\rho=0.5,2,3 \mathrm{~mm}$. For $\rho=0.5$ $\mathrm{mm}$, a geometry similar to the one proposed by Campagnolo and Berto [9] is examined.
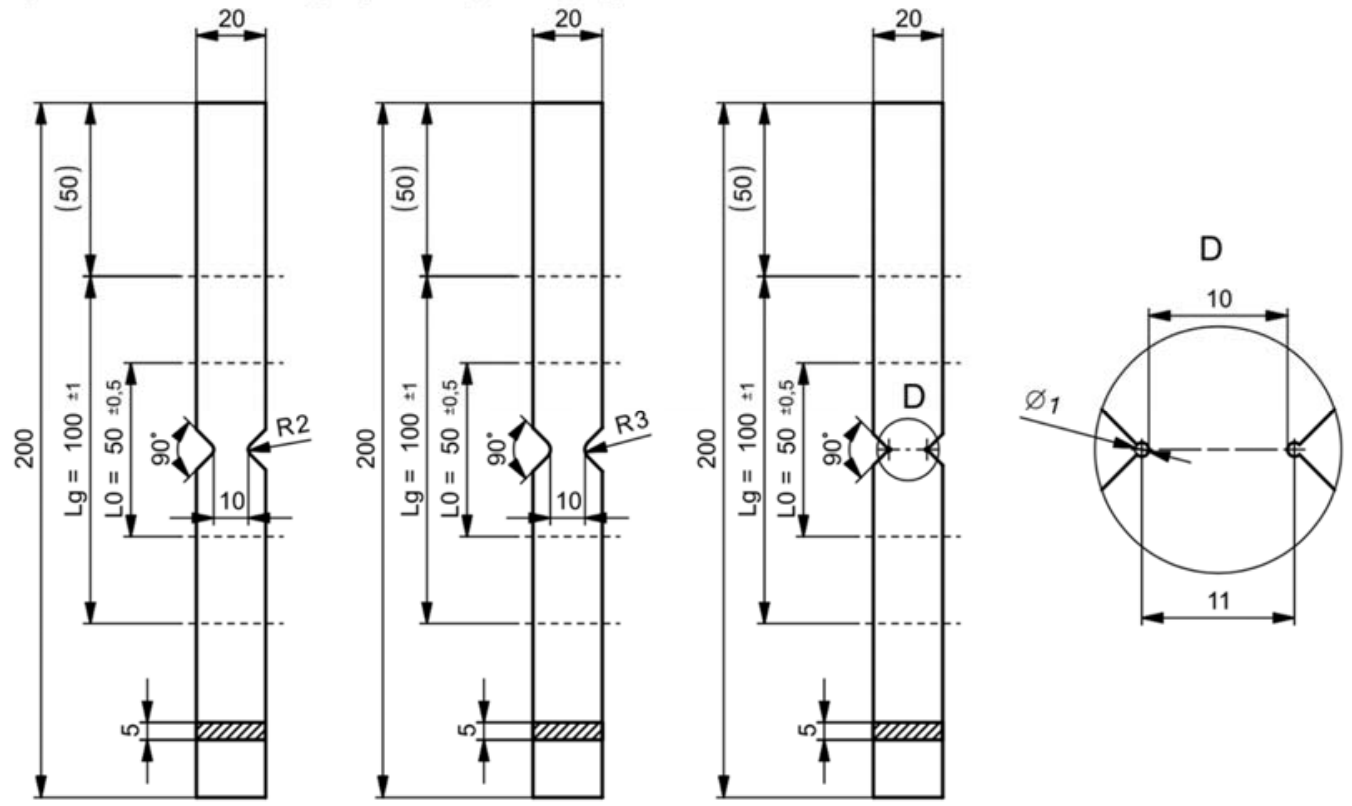

Figure 3: Specimens geometry for validation. 


\section{Manufacturing and Conditioning}

Specimens, made from industrial grade PMMA $5 \mathrm{~mm}$ thick sheet, were manufactured by milling. All the specimens belonging to the same series were machined jointly. The surface of the raw sheet was not finished. Specimens were not further conditioned.

\section{Experimental Testing}

Tensile tests were performed on a Zwick Roell Z050 universal testing machine (Zwick Roell Group, Ulm, DE), with a 5 $\mathrm{kN}$ load cell, $\pm 0.5 \%$ error at full scale, at room temperature. Tests were performed in a random order according to ISO 527 [17], with $25 \mathrm{~N}$ pre-load and test speed $5 \mathrm{~mm} / \mathrm{min}$. Elastic modulus is evaluated using regression, computed in strain ranging from $0.05 \%$ to $0.25 \%$, at test speed $0.5 \mathrm{~mm} / \mathrm{min}$.

\section{Finite Elements Analysis}

Finite element models are created with NX 12.0 (Siemens PLM Software, Plano, USA). Analysis are performed using NASTRAN solver (MSC Software Corporation, Newport Beach, USA). The necessary material properties not derived from the tensile test are obtained from relevant literature. Finite element models of the specimens were defined according to the dimensions of the notch root radius obtained with microscope images.

Linear elastic simulations are performed using the value of the failure load normalized for $A_{0}=50 \mathrm{~mm}^{2}$, so that the differences in cross-sectional area are considered:

$$
F_{n}=F_{c} \cdot \frac{50}{A_{0}}
$$

Quarter specimens are modeled with a 2D mesh with CTRIA(6) triangular parabolic elements, taking advantage of the double symmetry, with the appropriate boundary condition, to reduce model size and computational time. Sectors of the control volume according to Fig. 2 with radii varying from 0.005 to $0.05 \mathrm{~mm}$ are defined to evaluate the average value of the strain energy density. Mesh refinement up to size $0.002 \mathrm{~mm}$ is applied in the control volume to precisely compute the value, whereas the rest of the model is divided into elements of size $0.5 \mathrm{~mm}$, with a transition region to smoothly increase elements size. Material properties, typical for PMMA at room temperature [16], are reported in Tab. 1.

\begin{tabular}{ccc}
\hline Property & Value & Unit \\
Density & 1.18 & $\mathrm{~g} / \mathrm{cm}^{3}$ \\
Elastic Modulus & $3^{\prime} 000$ & $\mathrm{MPa}$ \\
Poisson's ratio & 0.4 & - \\
\hline
\end{tabular}

Table 1: PMMA properties for FEA.

The average value of the strain energy value is calculated as the total strain energy, computed within the control radius, divided by the undeformed volume, considering negligible displacement.

\section{RESULTS}

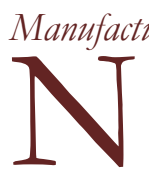

\section{acturing}

o particular problems were encountered during manufacturing. Specimens were measured with a caliper and pictures of a random specimen for each series were taken to evaluate the geometry of the notch. The width at the notch was tested to be within $\pm 3 \%$ of the nominal value $( \pm 0.3 \mathrm{~mm})$.

Specimens are within the dimensional tolerances for notch opening angle, thickness and minimal width, with a smooth surface finish. Sharp notched samples, except those with angle $90^{\circ}$, are characterized by a small root radius. V90R0 are treated in FEA as ideally sharp, while V60R 0 are modeled with a fillet radius of $\rho=0.045 \mathrm{~mm}$ and V45R 0 with $\rho=0.075 \mathrm{~mm}$, both being the lower bound of the measured values. Specimens with $45^{\circ}$ sharp notch show a small crack at the notch tip (Fig. 4a). 


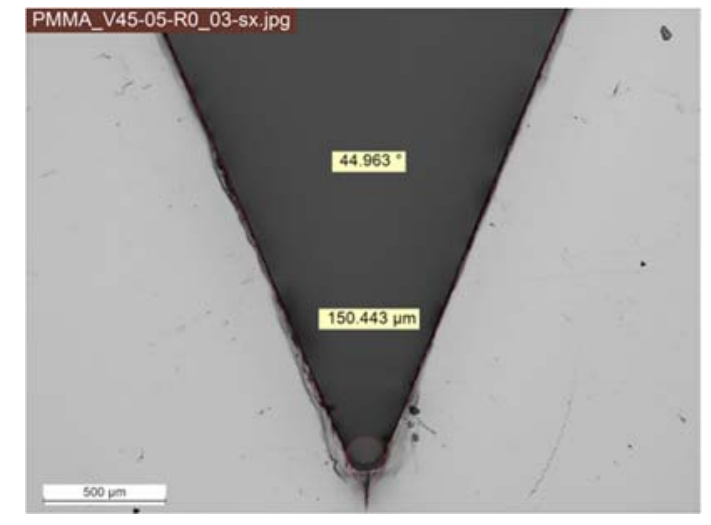

a

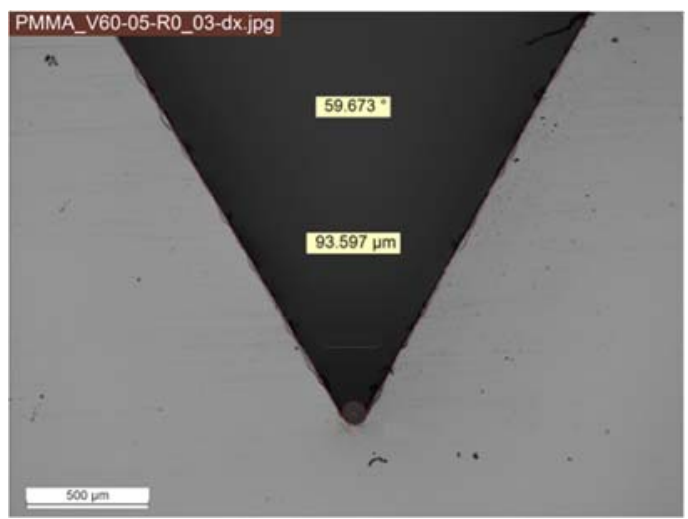

c

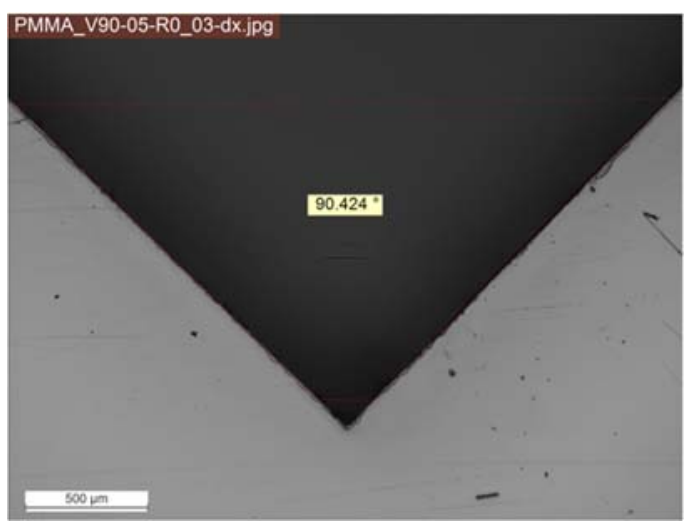

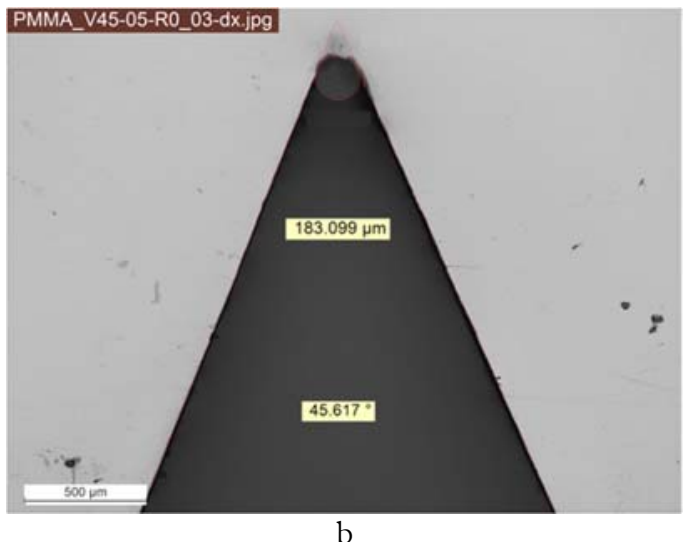

b
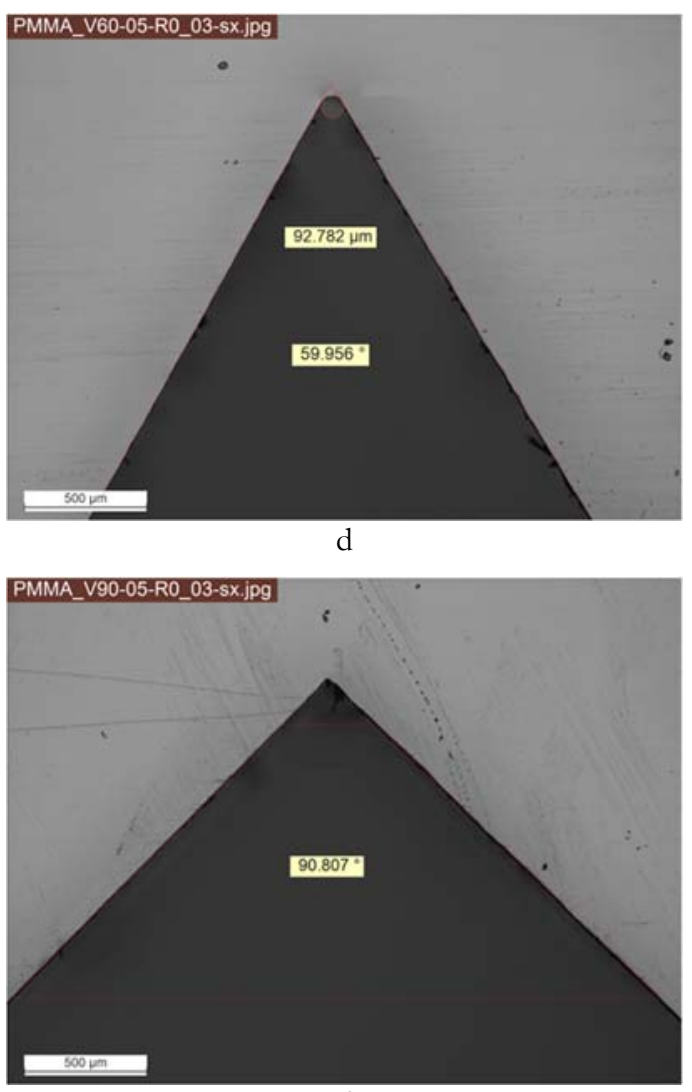

f

Figure 4: Sharp V-notch specimens dimension. 


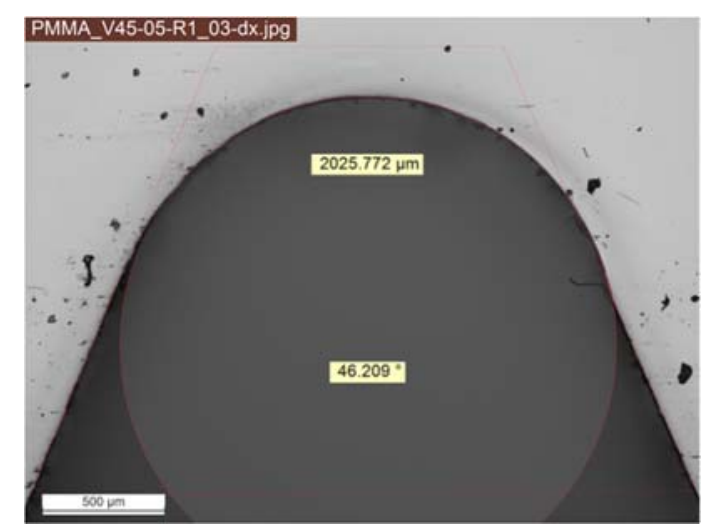

a

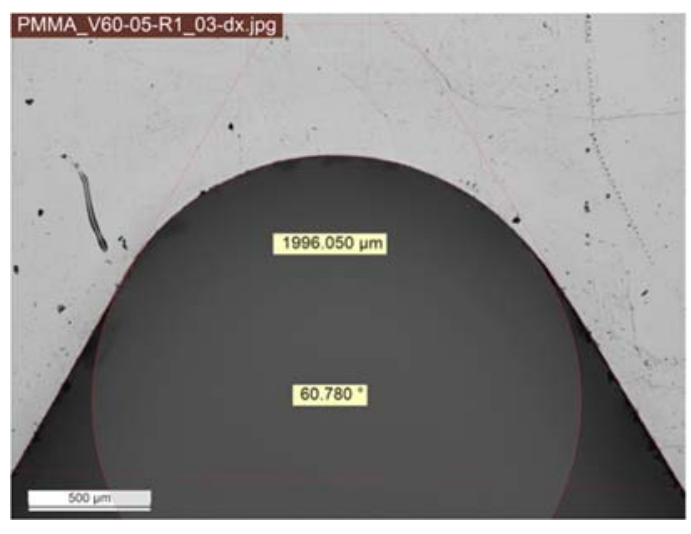

C

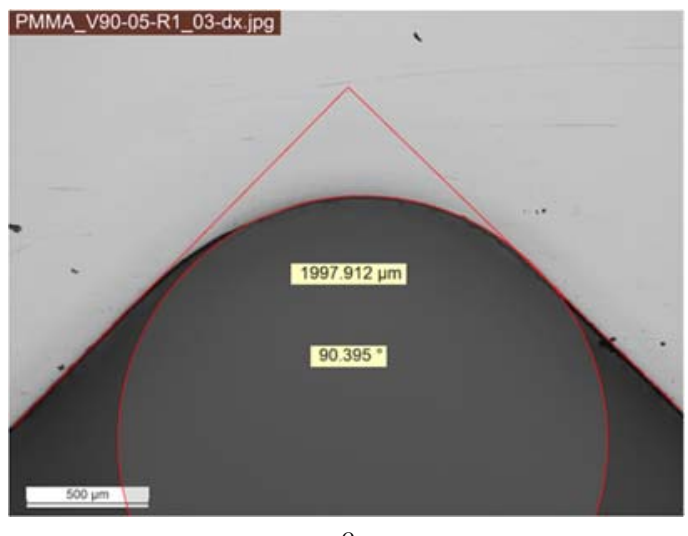

e

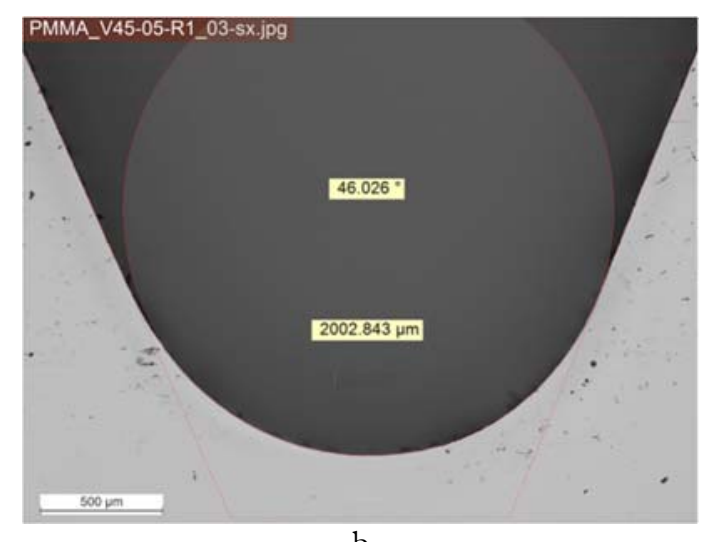

$\mathrm{b}$
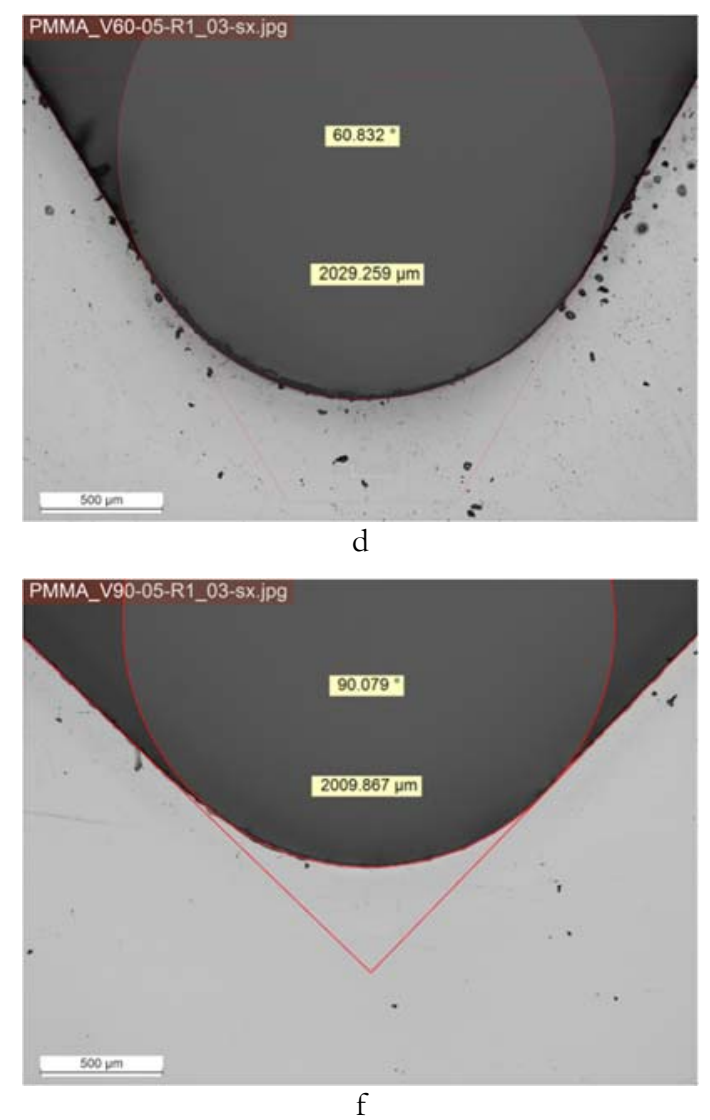

Figure 5: Blunt V-notch specimens dimension. 


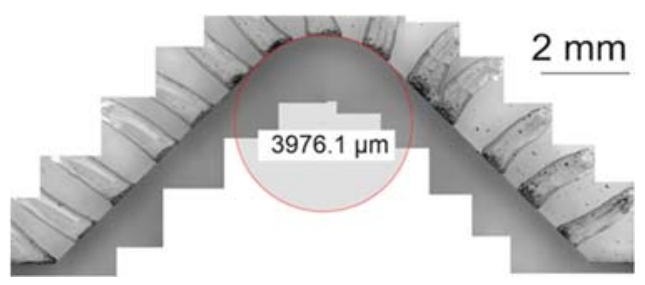

a
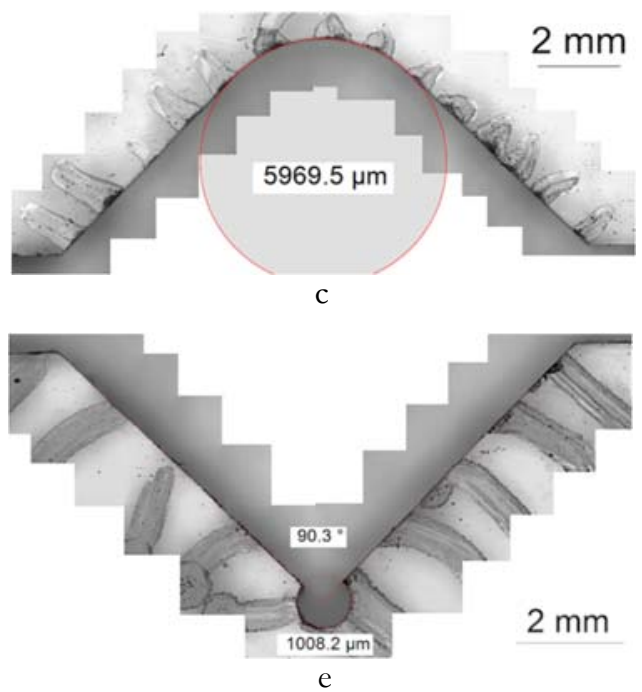
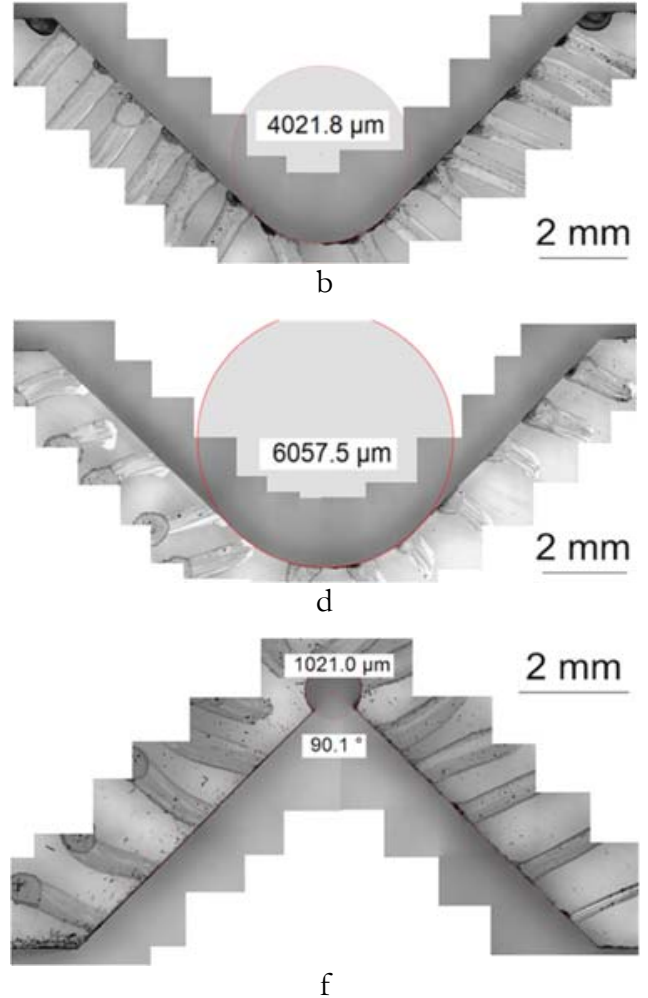

Figure 6: Validation specimens dimension.

Specimens for validation are also within tolerances (Fig. 6), with the width being $\pm 3 \%$ of the nominal value. On a side note, specimen with notch end hole are easier to manufacture.

\section{Tensile Tests}

All specimens broke with a flat smooth fracture surface perpendicular to the load axis without fragmentation, as Fig. 7 shows.

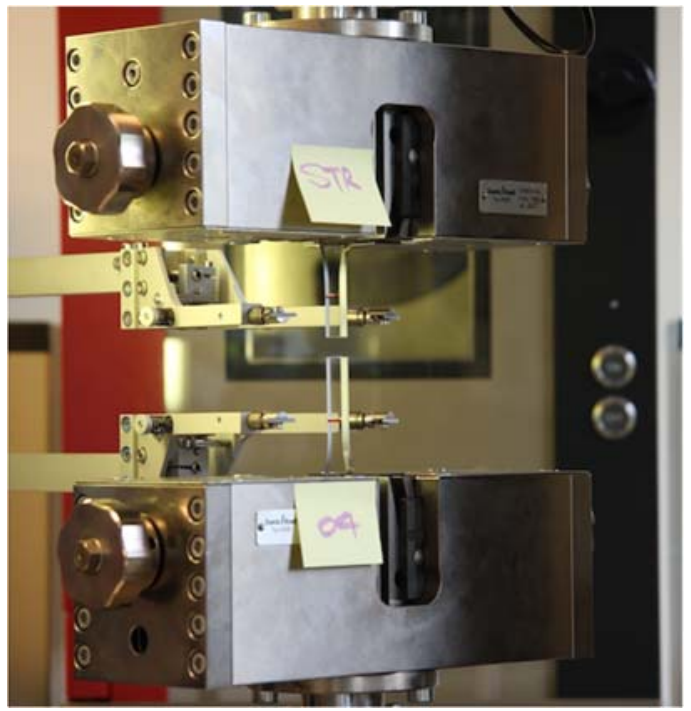

a

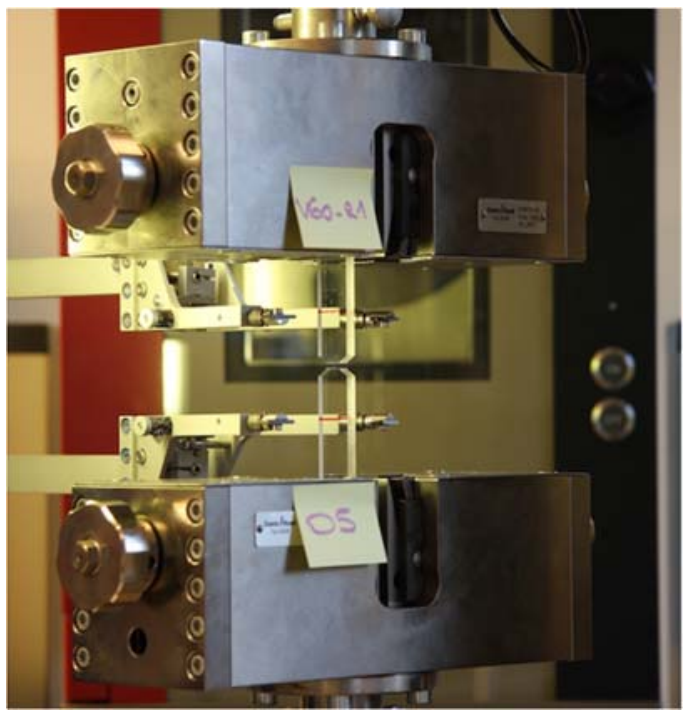

$\mathrm{b}$

Figure 7: Failed unnotched (a) and notched (b) samples. 
Results from the tensile tests are reported in Tabs. 2 and 3 and Figs. 8, 9 and 10. Unnotched specimen behavior is nonlinear with high and sparse strain values at break, which vary from 5.5\% to 10.7\%, but very consistent in stress-strain trend (Fig. 12). The average value of the elastic module of $3^{\prime} 000 \mathrm{MPa}$ is consistent with what found in literature for PMMA at room temperature $[18,16]$. Given that straight smooth specimen should have constant strain energy density across their section, this can be directly computed as the area under the stress-strain curve giving a mean value of $4.9 \mathrm{Nmm} / \mathrm{mm}^{3}$, a maximum of $6.8 \mathrm{Nmm} / \mathrm{mm}^{3}$ and a minimum of $2.9 \mathrm{Nmm} / \mathrm{mm}^{3}$.

\begin{tabular}{lrrrrrr}
\hline & $A_{0}\left[\mathrm{~mm}^{2}\right]$ & $\sigma_{u t}[\mathrm{MPa}]$ & $E[\mathrm{MPa}]$ & $\varepsilon_{r}[\%]$ & $F_{c}[\mathrm{~N}]$ & $\bar{W}_{c}\left[\mathrm{Nmm} / \mathrm{mm}^{3}\right]$ \\
STR_01 & 49.4 & 75.7 & 2870 & 5.5 & 3738 & 2.9 \\
STR_02 & 50.6 & 75.5 & 2960 & 8.2 & 3820 & 5.0 \\
STR_03 & 50.3 & 75.7 & 3090 & 8.5 & 3807 & 5.3 \\
STR_04 & 49.0 & 75.7 & 3140 & 10.7 & 3708 & 6.8 \\
STR_05 & 50.3 & 75.7 & 2940 & 7.3 & 3807 & 4.3 \\
\hline AVG & 49.9 & 75.7 & 3000 & 8.0 & 3777 & 4.9 \\
SD & 0.62 & 0.08 & 99.8 & 1.7 & 44.5 & 1.3 \\
\hline
\end{tabular}

Table 2: PMMA properties, results from tensile tests.

\begin{tabular}{|c|c|c|c|c|c|c|c|c|c|}
\hline & \multicolumn{9}{|c|}{$F_{c}[\mathrm{~N}]$} \\
\hline & V45R0 & V45R1 & V60R0 & V60R1 & V90R0 & V90R1 & V90R2 & V90R3 & V90R05 \\
\hline & 675 & 3005 & 843 & 2713 & 1103 & 2993 & 3306 & 3668 & 2008 \\
\hline & 722 & 2972 & 975 & 2840 & 1022 & 2739 & 3781 & 4012 & 1977 \\
\hline & 702 & 2823 & 983 & 2818 & 1015 & 3019 & 3767 & 3937 & 1956 \\
\hline & 754 & 2849 & 919 & 2845 & 1011 & 2986 & 3794 & 4154 & 1974 \\
\hline & 825 & 2791 & 915 & 2908 & 1062 & 3017 & 3734 & 3988 & 2086 \\
\hline AVG & 735 & 2888 & 927 & 2825 & 1042 & 2951 & 3676 & 3952 & 2000 \\
\hline SD & 52 & 85 & 51 & 63 & 35 & 107 & 186 & 159 & 46 \\
\hline
\end{tabular}

Table 3: Failure loads, results from tensile tests.

There is a very low scatter within series with no outliers. Specimens showed no evident permanent deformation, suggesting an elastic behavior. Whilst unnotched specimens showed a strongly nonlinear behavior (Fig. 8), notched ones failed in a quasi-brittle manner (Figs. 9 and 10).

It is worth noting that the slope of the load-displacement curve is similar for all the notched specimens, i.e. the apparent specimen rigidity is independent from notch parameters. 


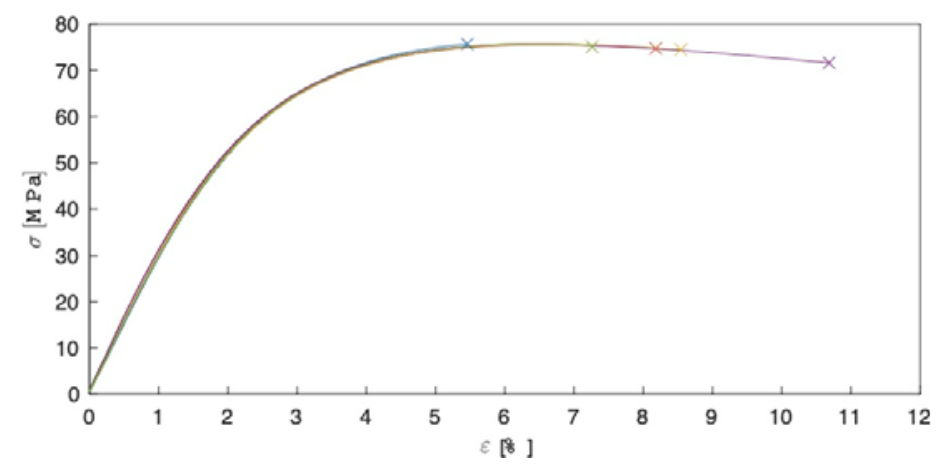

Figure 8: Stress-strain curves for unnotched specimens.
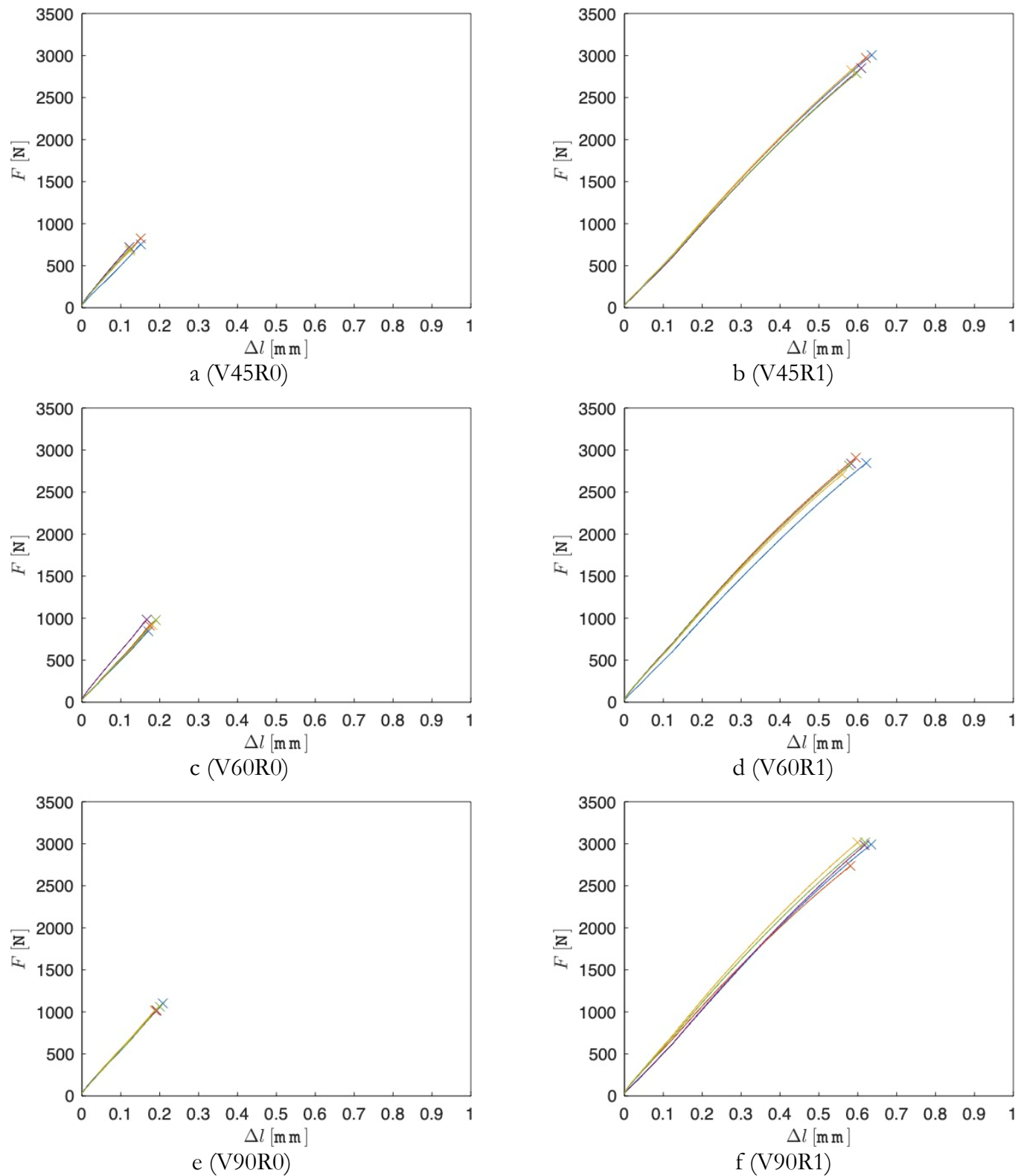

Figure 9: Load-displacement curve of notched specimen. 
Whilst specimens with end hole at the notch tip maintain a brittle behavior, those characterized by a bigger notch root radius begin to have a nonlinear trend before failure.
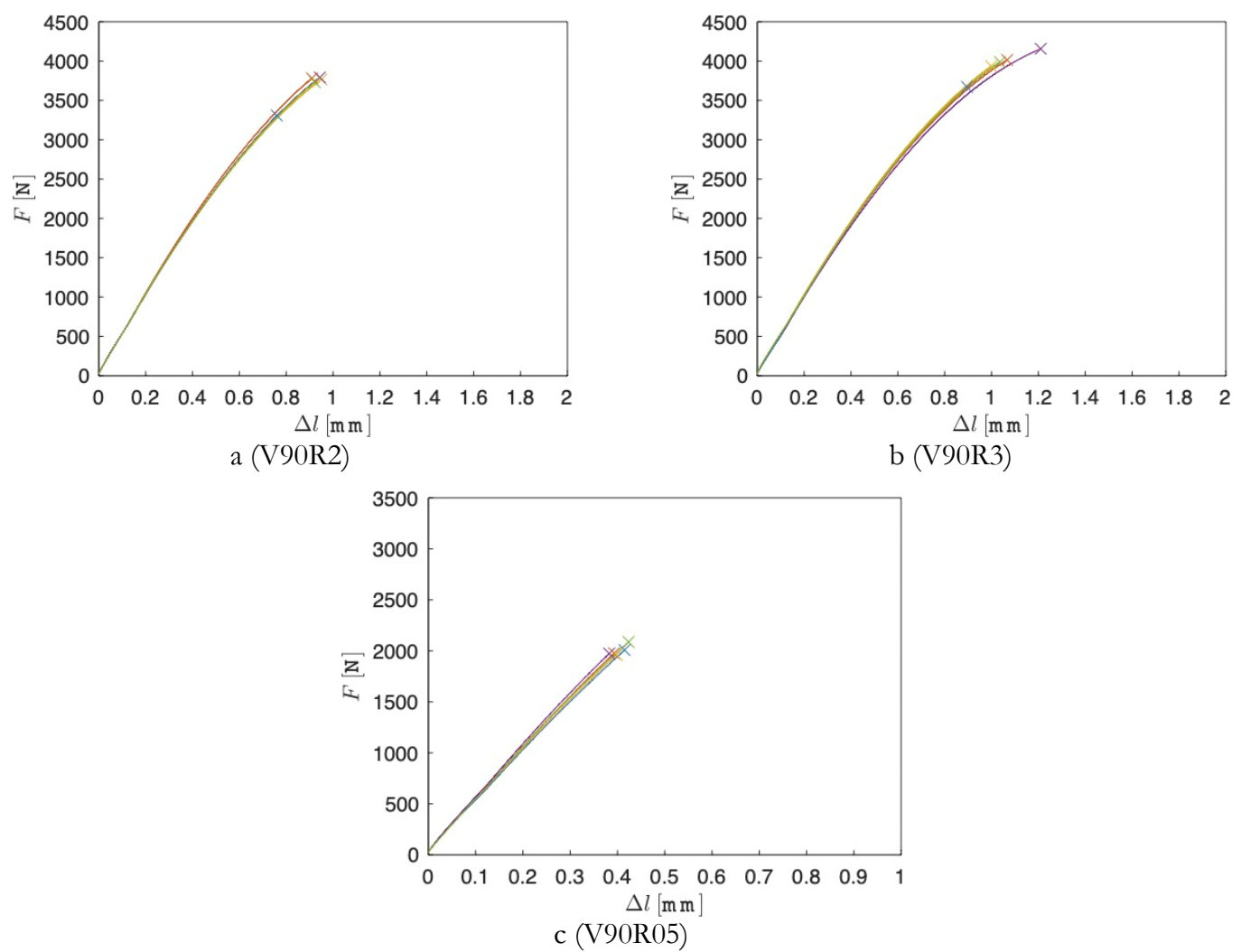

Figure 10: Load-displacement curve of validation samples.

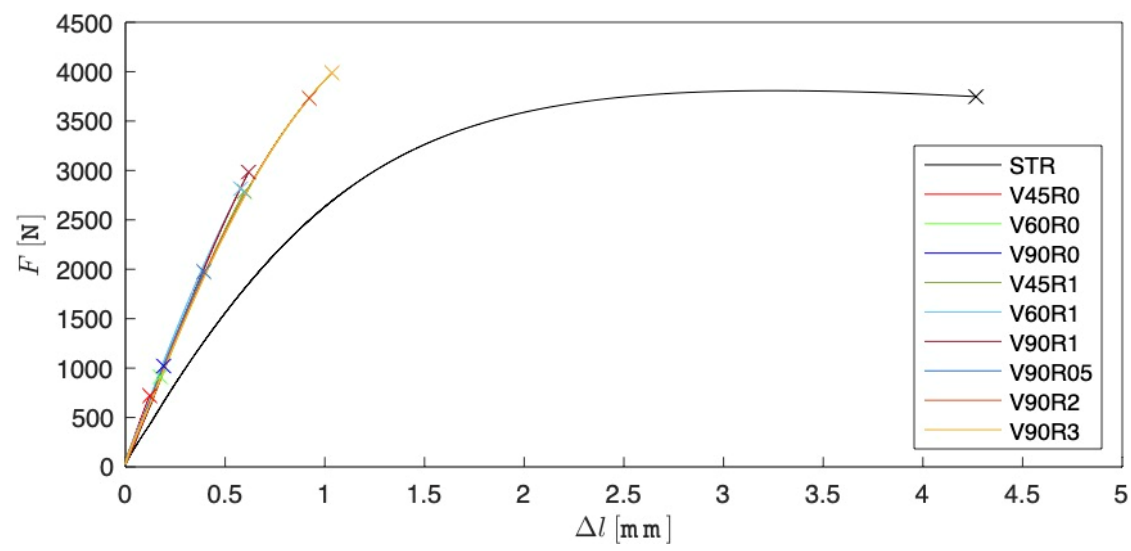

Figure 11: Comparison of the load-displacement curves for all specimens (for each series the most representative is shown).

\section{Finite Element Analysis}

For every series of specimens, the mean, maximum and minimum value of the failure load are considered to compute the strain energy density. For the sake of clarity, only the mean values are considered in this section. Fig. 12 shows the value of the average strain energy density as a function of the control radius. Blunt notch samples show a nearly constant SED, with imperceptible difference between notch opening angles, whereas the mean SED decays with a likely exponential trend for sharp V-notches. V90R0 and V60R0 samples cross the other curves at $R_{0}=0.02 \mathrm{~mm}$ and $R_{0}=0.015 \mathrm{~mm}$, respectively. V45R 0 samples have a lower average value of SED in the range of control radii considered here. 


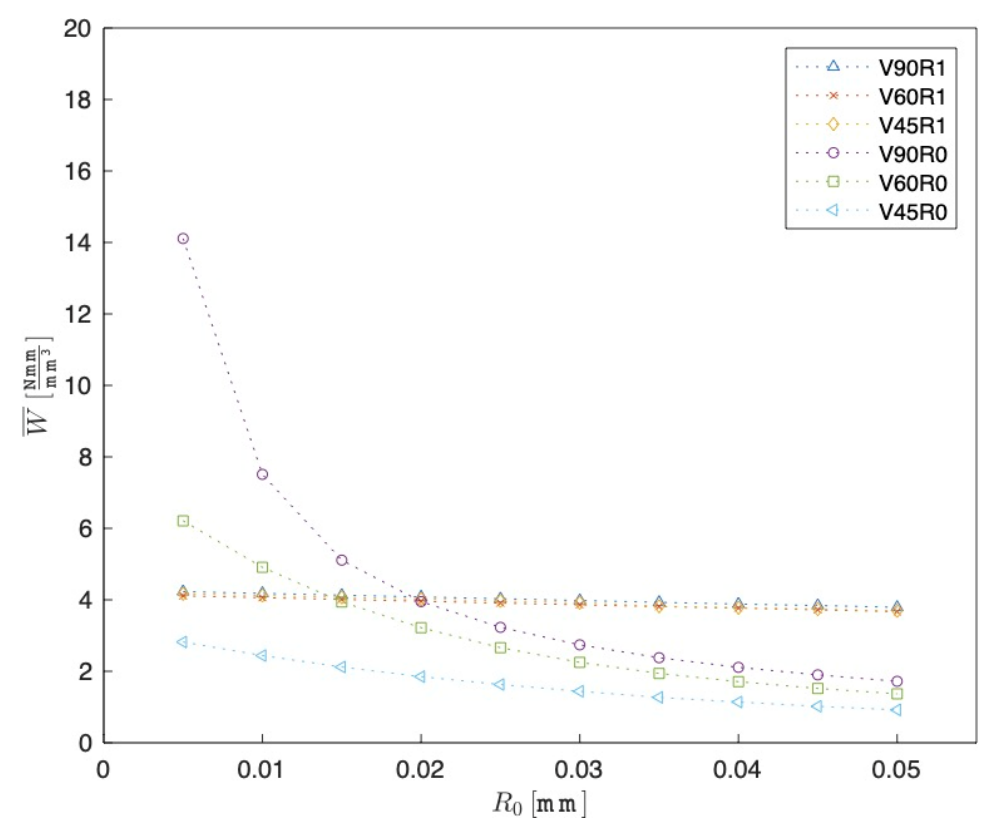

Figure 12: Average SED in function of the control radius (FEA under plane strain condition).

In general, what observed for plane strain condition holds true for plane stress, only with higher values of the average SED, as shown in Fig. 13. In this case, the crossing point for V90R0 specimens occurs near $R_{0}=0.025 \mathrm{~mm}$.

For both plane strain and plane stress conditions, V45R0 samples seem to be outliers with lower average strain energy density than the other specimens. For this series a crack was observed at the notch tip (Fig. 4a), which could be the cause for a premature failure. Modeling the crack is not possible because its dimension and shape are uncertain. These specimens are therefore excluded from the analysis.

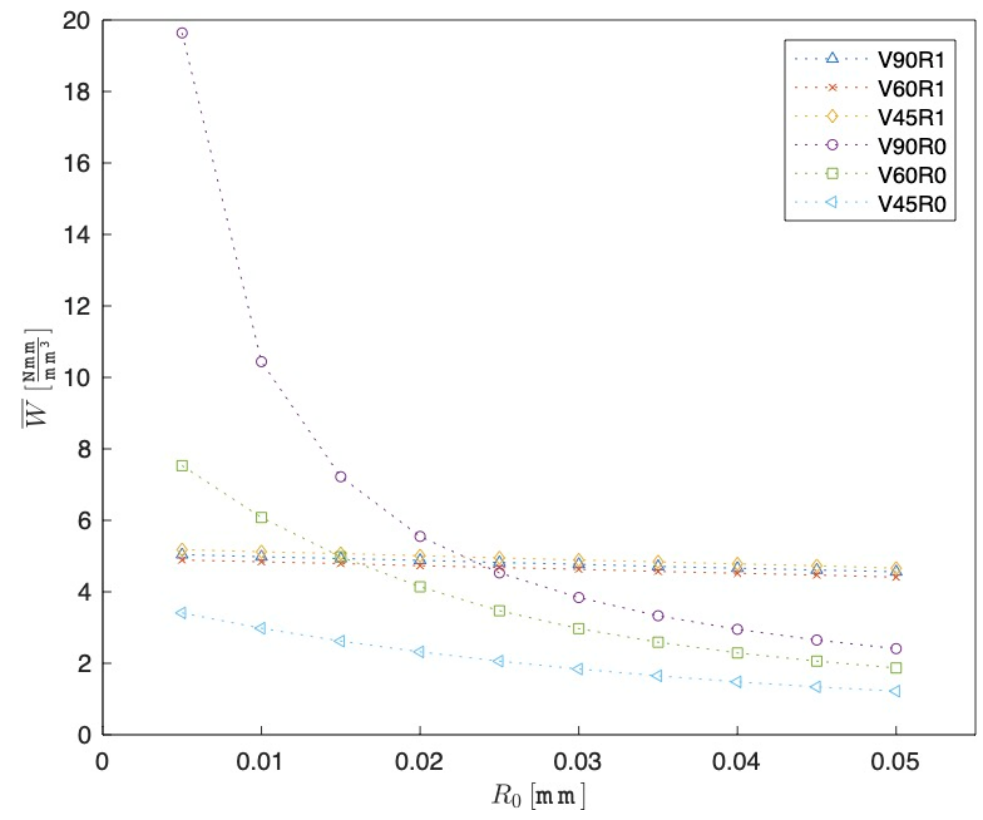

Figure 13: Average SED in function of the control radius (FEA under plane stress condition). 


\section{Discussion}

\section{Critical Value of the SED and Optimal Control Radius}

1 o find the optimal control radius, the variance of the average SED value of all the series of samples is computed, the optimal radius should be the one for which all the values have the least scatter. Fig. 14 plots the variance and mean of the average SED for all the samples considered as a function of the control radius $R_{0}$. For both plane stress and plane strain condition, among the radii investigated, $R_{0}=0.02 \mathrm{~mm}$ has the lowest variability.

Control radius for planar problems can be analytically evaluated with Eqns. 7 and 6 . Using $v=0.4, K_{\mathrm{IC}}=1.0 \mathrm{MPa} \cdot \mathrm{m}^{1 / 2}[16]$ and $\sigma_{\mathrm{ut}}=75.0 \mathrm{MPa}$, we obtain $R_{0}=0.054 \mathrm{~mm}$ for plane stress condition and $R_{0}=0.036 \mathrm{~mm}$ for plane strain condition, both being incorrect for the investigated experimental data, but there is an uncertainty on fracture toughness value.

Various values of R0 have been found in literature for the SED criterion using PMMA at room temperature: $R_{0}=0.028 \mathrm{~mm}$ [19], $R_{0}=0.016 \mathrm{~mm}$ [14], $R_{0}=0.011 \mathrm{~mm}$ [16], $R_{0}=0.035 \mathrm{~mm}$ [16]. The control radius obtained in this work $\left(R_{0}=0.02 \mathrm{~mm}\right)$ remains in the range of results found by previous paper. Tab. 4 lists the critical SED, evaluated for both plane stress and plane strain condition, and its boundary, being the highest and lowest value computed, considering all the samples.

\begin{tabular}{lccc}
\hline & \multicolumn{3}{c}{$\bar{W}_{c}\left[\mathrm{Nmm} / \mathrm{mm}^{3}\right]$} \\
\cline { 2 - 4 } & $\min$ & mean & $\max$ \\
Plane stress & 3.69 & 4.86 & 6.20 \\
Plane strain & 2.87 & 3.85 & 4.46 \\
\hline
\end{tabular}

Table 4: Maximum, mean and minimum values of the critical SED.

Under plane stress condition, the critical SED value has a higher scatter, but there is a better agreement with experimental results, being $\bar{W}_{c}=4.9 \mathrm{Nmm} / \mathrm{mm}^{3}$ the mean value measured for the smooth specimens.

Partly, the underestimated value of $\bar{W}_{c}$ in plane strain condition is explained by the fact that the plane strain elastic modulus is $E /\left(1-v^{2}\right)$, scaling the results by 0.84 with the properties of the PMMA considered in this work.

Albeit the higher discrepancy with experimental data, the plane strain condition is preferable because it better represent the tri-axial state of stress near the notch tip. Nevertheless, both plane conditions are approximation for the situation here investigated, but these results confirm that it can be treated as planar problem with satisfactory accuracy.

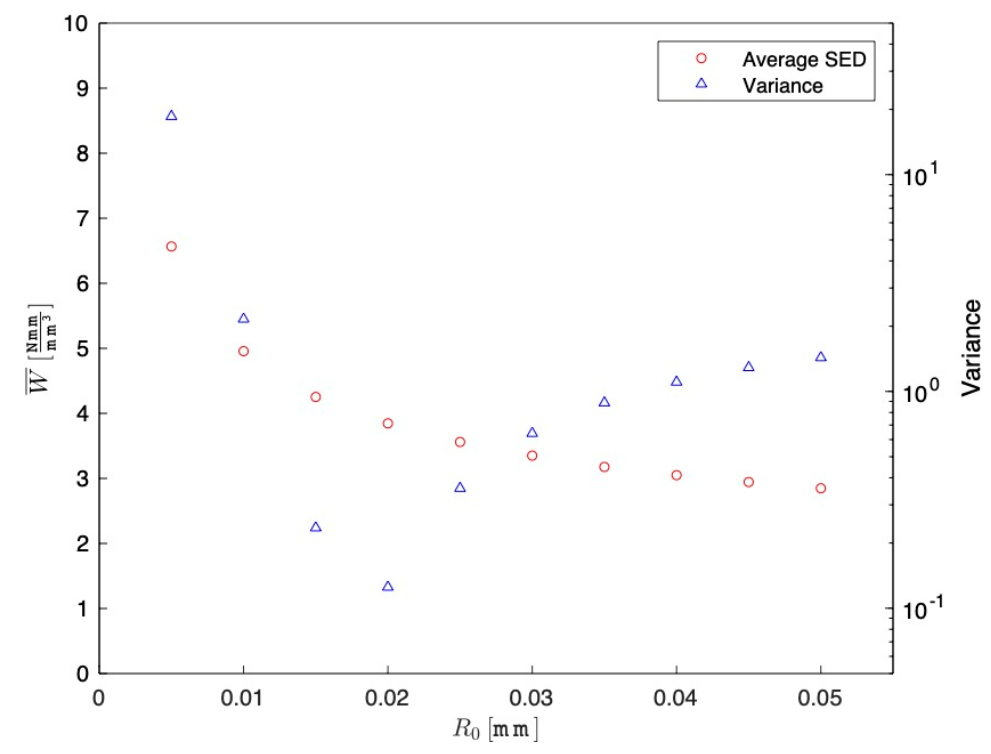

Figure 14: Mean SED and variance for the different series of specimen (FEA under plane strain condition, excluding V45R0). 


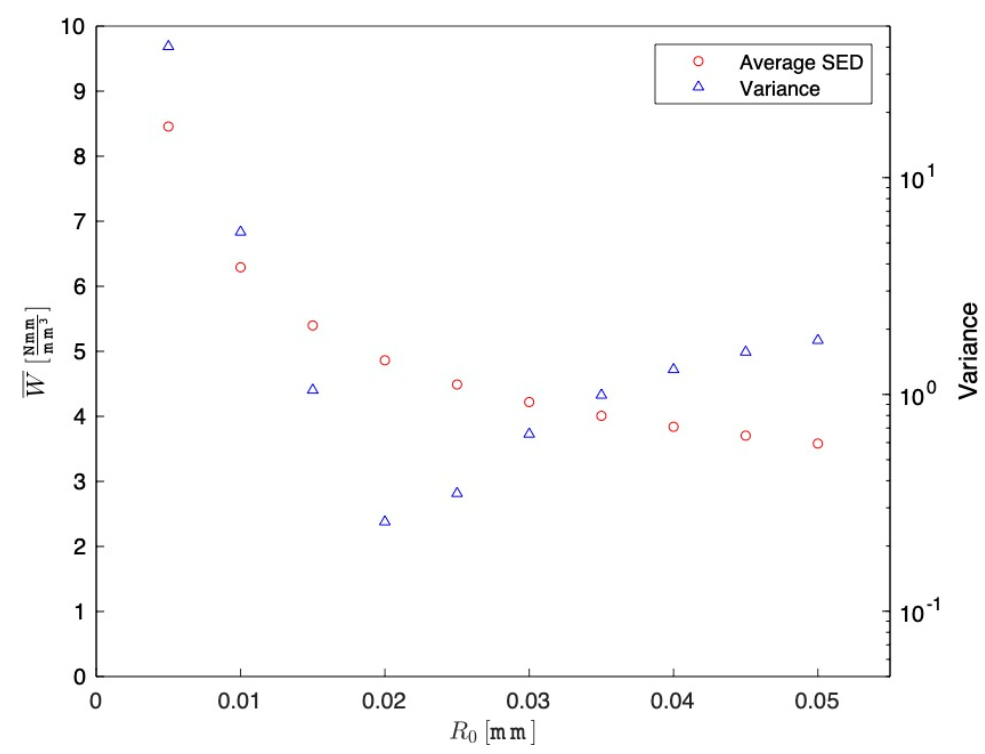

Figure 15: Mean SED and variance for the different series of specimen (FEA under plane stress condition, excluding V45R0).

\section{Shape of the Control Volume}

The criterion is based on the average SED value, valuated in a small but finite volume around the notch tip, which has a circular shape. Lazzarin and Berto observed that the center of the strain energy density isocurves is located approximately at the midpoint between notch tip and root radius center when $2 \alpha=0$, and progressively approaches the tip with decreasing opening angle and root radius [16]. The control volume encloses a part of the rectilinear notch flanks when the root radius $\rho$ is smaller than $R_{0}$, but the shape of the curves remains circular.

For ideally sharp V-notches, the curves assume a crescent shape in the direction perpendicular to the notch bisector line, as shown in Fig. 16a. In this case, the circular control volume is clearly not well representing the trend of the SED, but the FEA results still show good agreement with experimental data. In reality, all notches are blunt to some extent, this means that there is always a small volume near the notch tip where the SED isocurves have a circular shape.

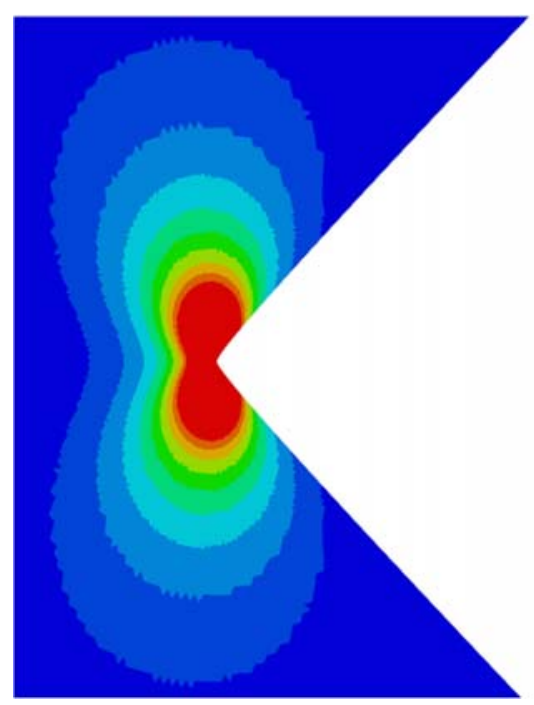

a (Sharp V-notch, $\rho=0 \mathrm{~mm}$ )

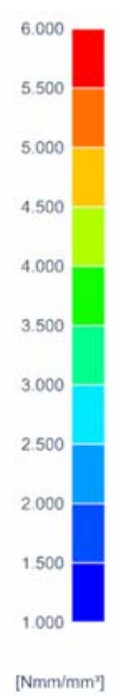

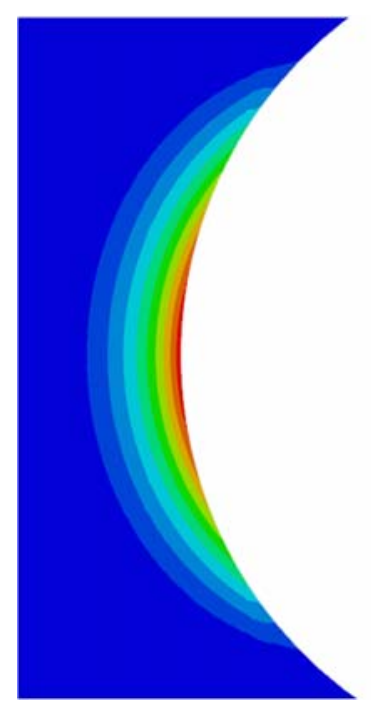

b (Blunt V-notch, $\rho=1 \mathrm{~mm})$

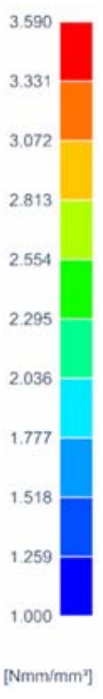

$\left[\mathrm{Nmm} / \mathrm{mm}^{2}\right]$

Figure 16: Strain Energy distribution around the notch tip for $90^{\circ}$ notch opening angle subjected to the critical load (FEA under plane strain condition). 


\section{Notch Effect}

Fig. 17 shows the failure loads, normalized to $A_{0}=50 \mathrm{~mm}^{2}$, as a function of notch opening angle. There is very low scatter for samples up to $\rho=1 \mathrm{~mm}$. The root radius has a much higher influence than the angle, with the loads slightly decreasing with notch opening angle for sharp notches and with negligible difference for blunt specimens with root radius $1 \mathrm{~mm}$. Lazzarin and Berto observed that the notch opening angle has no influence for $R_{0} / \rho$ ratios less than 0.2 [16], which means that, in this case, the notch opening angle should be irrelevant above $\rho=0.1 \mathrm{~mm}$.

For $\rho \geq 2 \mathrm{~mm}$ the specimens withstand higher loads compared to smooth unnotched samples, suggesting a notch strengthening mechanism for PMMA. However, the present data is insufficient to further investigate this behavior and, being temperature and humidity uncontrolled during storage and testing there is some uncertainty whether this could be the cause for such small variation, as some previous researches demonstrate [20]. Moreover, these sets of specimens show wider scatter than the others and have a nonlinear behavior before failure.

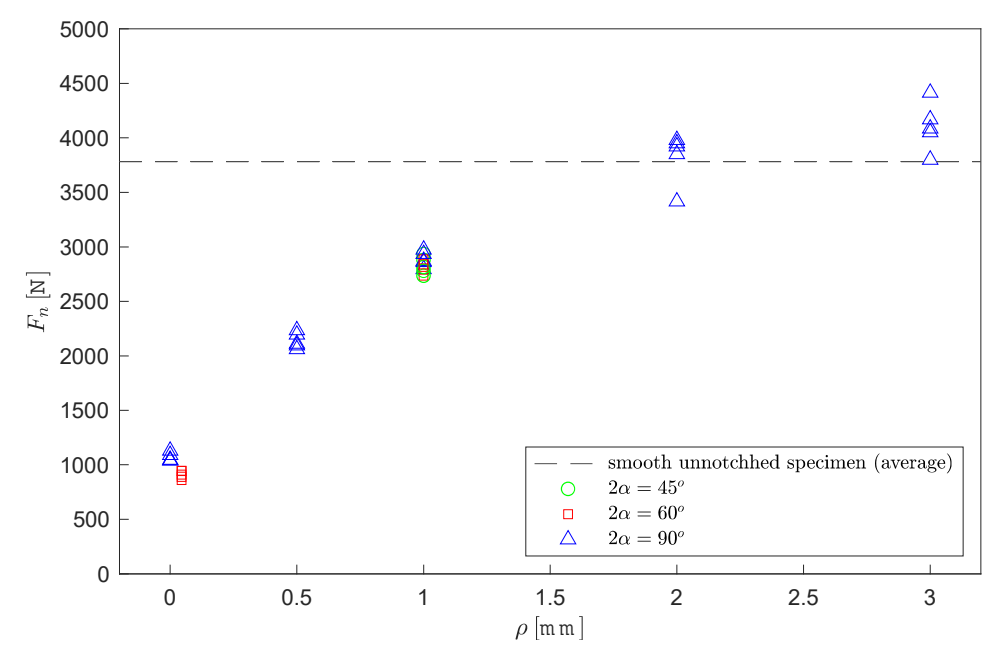

Figure 17: Normalized failure loads as a function of the notch opening angle.

\section{Validation}

For linear elastic behavior, the value of the SED is directly proportional to the stress (Eqn. 3), the same is obviously true for the applied load:

$$
\bar{W} \propto F^{2}
$$

This relationship allows to estimate the failure load valuating the SED via FEA with an arbitrary load:

$$
\frac{\bar{W}}{F^{2}}=\frac{\bar{W}_{c}}{F_{c}^{2}}
$$

Thus:

$$
F_{c}=\sqrt{\frac{\bar{W}_{c}}{\bar{W}}} \cdot F^{2}
$$

Tab. 5 summarizes the prediction of the failure load for the validation samples. For the sake of simplicity, only the mean value is considered. The predicted loads are always within $\pm 15 \%$ of the measured value, in most case the discrepancy is below $10 \%$. In this case, the plane stress condition seems to be more representative. 
The predicted values of the loads are also sufficiently accurate when a possible notch strengthening mechanism is observed. However, the value of the SED is underestimated when treating nonlinear behavior as linear elastic (Fig. 18). This means that, in this case, the predicted loads are overestimated. Again, more data is needed to better assess the problem.

\begin{tabular}{lrrrrr}
\hline & Measured & \multicolumn{2}{c}{ Predicted, plane stress } & \multicolumn{2}{c}{ Predicted, plane strain } \\
\cline { 2 - 6 } & $F_{n}[\mathrm{~N}]$ & $\hat{F}_{n}[\mathrm{~N}]$ & error $[\%]$ & $\hat{F}_{n}[\mathrm{~N}]$ & error $[\%]$ \\
V90R05 & 2139 & 2125 & -0.7 & 2328 & 8.1 \\
V90R2 & 3823 & 3789 & -0.9 & 4251 & 10.1 \\
V90R3 & 4104 & 4420 & 7.2 & 4826 & 15.0 \\
\hline
\end{tabular}

Table 5: Predicted normalized failure loads.

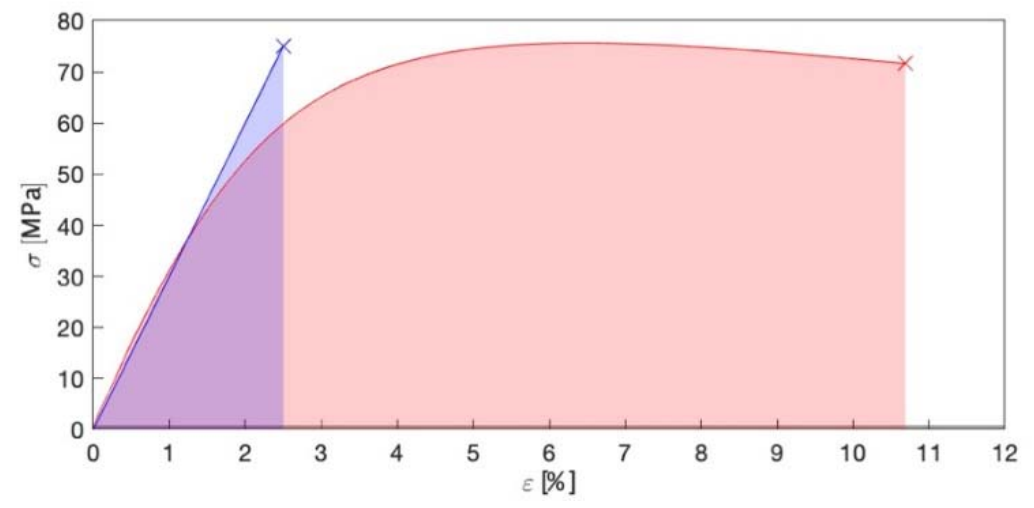

Figure 18: Comparison between real behavior of PMMA and its linear elastic approximation.

\section{Method Evaluation}

Being the SED proportional to the squared value of the load (Eqn. 10), for practical purposes, it is meaningful to compare the squared values of the SED. Fig. 19 and 20 plot the average value of the SED inside the control volume of $R_{0}=0.02 \mathrm{~mm}$, normalized to the critical value for both plane stress and plane strain condition. For each series of specimens, the maximum, mean and minimum normalized load is considered.

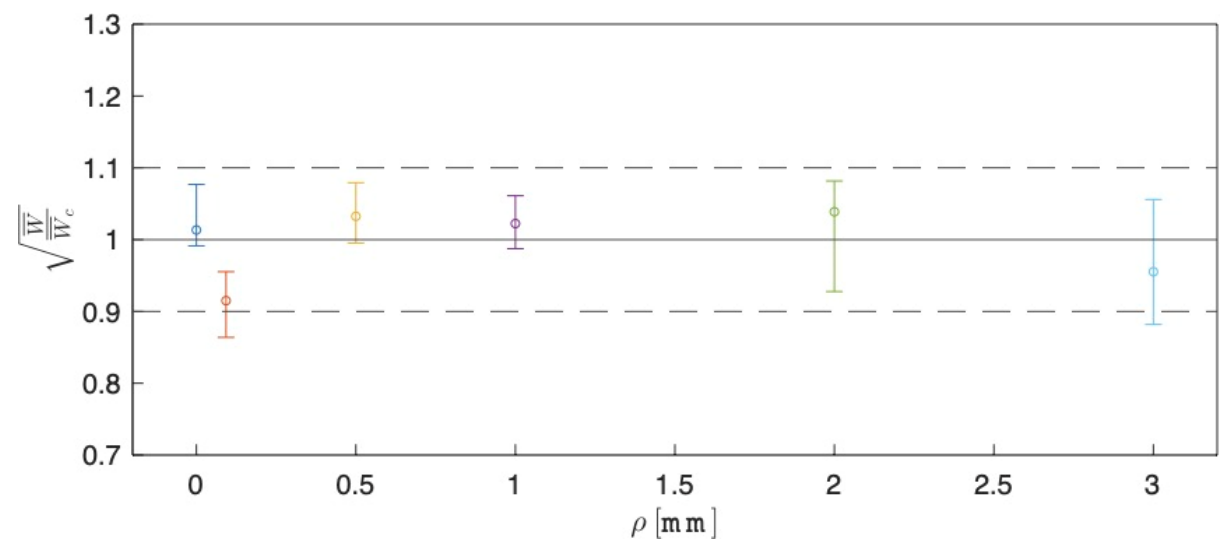

Figure 19: Scatter of the ratio of the SED over its critical value for all the specimens sampled in this work, considering mean, max and mean values from the tensile test (V45R0 specimens excluded), for plane strain condition. 


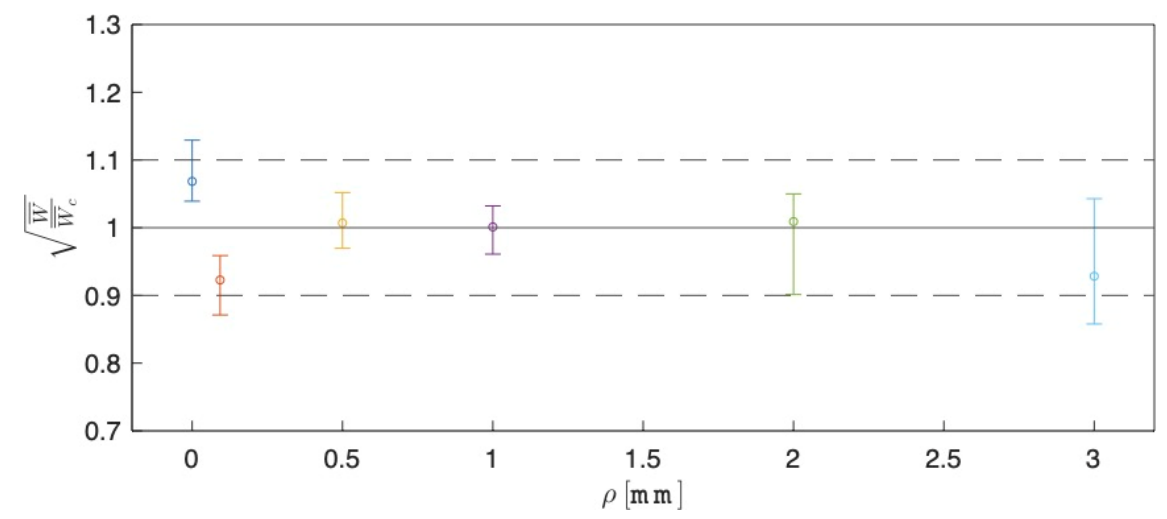

Figure 20: Scatter of the ratio of the SED over its critical value for all the specimens sampled in this work, considering mean, max and mean values from the tensile test (V45R0 specimen excluded), for plane stress condition.

In both cases, the scatter is very limited, with most series being under $\pm 10 \%$ the critical value. Under plane strain condition, predictions are generally more accurate.

These results suggest that it is possible to compute the SED via FEA under linear elastic hypothesis even if the material highlights a nonlinear behavior, as long as the behavior of the notched component is brittle or quasi-brittle, as already observed by Lazzarin and Zambardi [3].

\section{CONCLUSION}

$\mathrm{I}$ $\mathrm{n}$ this work, the static failure in mode I loading has been investigated using a new set of experimental data obtained using smooth and notched specimens of PMMA. In particular, a large variability of notch root radius and notch opening angle was considered.

Although PMMA shows a strongly nonlinear behavior at room temperature, notched specimens fail in a brittle manner, with load-displacement slope independent from the notch dimensions. It has been observed that the notch root radius $\rho$ has a much higher influence on the strength of the specimen than the opening angle of the notch, which becomes relevant only for $\rho<0.1 \mathrm{~mm}$.

The criterion based on the average strain energy density in a finite volume surrounding the notch tip has been applied to the experimental data. Finite element analysis' have been computed to numerically evaluate the strain energy density of the specimens at failure, considering the material as ideally linear elastic and both plane stress and plane strain conditions were examined. The value of the control radius, has been determined to be $R_{0}=0.02 \mathrm{~mm}$.

The hypothesis of plane strain was more accurate to predict the failure load, but the critical strain energy density computed using finite elements analysis' under plane stress condition $\left(\bar{W}_{c}=4.86 \mathrm{Nmm} / \mathrm{mm}^{3}\right)$ was closer to the value directly measured by means of tensile tests.

A prediction based on a linear elastic material behavior showed very good agreement with experimental data, with an error that in most cases remains in the range of $\pm 10 \%$.

A notch strengthening behavior has been observed for large values of the notch root radius, but it needs to be investigated with more experimental data, because with the present data samples there is some uncertainty about its relevance. 


\section{NOMENCLATURE}

$2 \alpha \quad$ Notch opening angle

$\varepsilon \quad$ Engineering strain

$\varepsilon_{r} \quad$ Strain at break

$\sigma \quad$ Engineering stress

$\sigma_{u t} \quad$ Ultimate tensile stress

$v \quad$ Poisson's ratio

$\rho \quad$ Notch root radius

$A_{0} \quad$ Initial section area

E Elastic modulus

F Force
$F_{c} \quad$ Failure load

$F_{n} \quad$ Failure load normalized on nominal section

$K_{I C} \quad$ Fracture toughness

$\mathrm{R}_{0} \quad$ Control radius

$r_{0} \quad$ Control volume center to notch tip distance

V Volume

$W \quad$ Strain energy

$\bar{W} \quad$ Strain energy density

$\bar{W}_{c} \quad$ Critical value of the strain energy density

\section{REFERENCES}

[1] Erdogan, F. and Sih. G.C. (1963). On the crack extension in plates under plane loading and transverse shear, Journal of Basic Engineering, 85(4), pp. 519-525. DOI: 10.1115/1.3656897.

[2] Lazzarin, P., Berto, F. and Zappalorto, M. (2010). Rapid calculations of notch stress intensity factors based on averaged strain energy density from coarse meshes: theoretical bases and applications, International Journal of Fatigue, 32(10), pp. 1559-1567. DOI: 10.1016/j.ijfatigue.2010.02.017.

[3] Lazzarin, P. and Zambardi, R. (2001). A finite-volume-energy based approach to predict the static and fatigue behavior of components with sharp v-shaped notches, International Journal of Fracture, 112(3), pp. 275-298.

DOI: 10.1023/A:1013595930617.

[4] Lazzarin, P. and Zambardi, R. (2002). The equivalent strain energy density approach re-formulated and applied to sharp v-shaped notches under localized and generalized plasticity, Fatigue \& Fracture of Engineering Materials \& Structures, 25(10), pp. 917-928. DOI: 10.1046/j.1460-2695.2002.00543.x.

[5] Berto, F. and Lazzarin, P. (2009). A review of the volume-based strain energy density approach applied to v-notches and welded structures, Theoretical and Applied Fracture Mechanics, 52(3), pp. 183-194.

DOI: $10.1016 /$ j.tafmec.2009.10.001.

[6] Lazzarin, P., Berto, F., Gomez, F.J. and Zappalorto, M. (2008). Some advantages derived from the use of the strain energy density over a control volume in fatigue strength assessments of welded joints, International Journal of Fatigue, 30(8), pp. 1345-1357. DOI: 10.1016/j.ijfatigue.2007.10.012.

[7] Radaj, D., Berto, F. and Lazzarin, P. (2009). Local fatigue strength parameters for welded joints based on strain energy density with inclusion of small-size notches, Engineering Fracture Mechanics, 76(8), pp. 1109-1130. DOI: 10.1016/i.engfracmech.2009.01.009.

[8] Berto, F. and Lazzarin, P. (2014). Recent developments in brittle and quasi-brittle failure assessment of engineering materials by means of local approaches, Materials Science and Engineering: R: Reports, 75, pp. 1-48. DOI: 10.1016/j.mser.2013.11.001.

[9] Campagnolo, A. and Berto, F. (2015). Tensile fracture analysis of blunt notched PMMA specimens by means of the strain energy density, Engineering Solid Mechanics, 3(1), pp. 35-42.

[10] Torabi, A.R., Campagnolo, A. and Berto, F. (2015). Local strain energy density to predict mode II brittle fracture in brazilian disk specimens weakened by v-notches with end holes, Materials \& design, 69, pp. 22-29. DOI: 10.1016/i.matdes.2014.12.037.

[11] Ayatollahi, M.R., Moghaddam, M.R., Razavi, S.M.J. and Berto, F. (2016). Geometry effects on fracture trajectory of PMMA samples under pure mode-I loading, Engineering Fracture Mechanics, 163, pp. 449-461.

DOI: 10.1016/j.engfracmech.2016.05.014.

[12] Berto, F. and Gomez, G. (2017). Notched plates in mixed mode loading (I+II): a review based on the local strain energy density and the cohesive zone mode, Engineering Solid Mechanics, 5(1), pp. 1-8. DOI: 10.5267/j.esm.2016.11.002. 
[13] Seweryn, A. (1994). Brittle fracture criterion for structures with sharp notches, Engineering Fracture Mechanics, 47(5), pp. 673-681. DOI: 10.1016/0013-7944(94)90158-9.

[14] Yosibash, Z., Bussiba, A. and Gilad, I. (2004). Failure criteria for brittle elastic materials, International Journal of Fracture, 125, pp. 307-333. DOI: 10.1023/B:FRAC.0000022244.31825.3b.

[15] Lazzarin, P. and Berto, F. (2005). From Neuber's elementary volume to Kitagawa and Atzori's diagrams: an interpretation based on local energy, International Journal of Fracture, 135(1-4): L33-L38. DOI: 10.1007/s10704-005-4393-x.

[16] Lazzarin, P. and Berto, F. (2005). Some expressions for the strain energy in a finite volume surrounding the root of blunt v-notches, International Journal of fracture, 135(1-4), pp. 161-185. DOI: 10.1007/s10704-005-3943-6.

[17] International Organization for Standardization (2019). ISO 527:2019 Plastics - determination of tensile properties - part 1: General principles, ISO Standard, Geneva, $\mathrm{CH}$.

[18] Johnson, J.A. and Jones, D.W. (1994). The mechanical properties of PMMA and its copolymers with ethyl methacrylate and butyl methacrylate, Journal of materials science, 29(4), pp. 870-876. DOI: 10.1007/BF00351404.

[19] Seweryn, A. and Lukaszewicz, A. (2002). Verification of brittle fracture criteria for elements with v-shaped notches, Engineering fracture mechanics, 69(13), pp. 1487-1510. DOI: 10.1016/S0013-7944(01)00138-2.

[20] Atkins, A.G., Lee, C.S., and Caddell, R.M. (1975). Time-temperature dependent fracture toughness of PMMA. Journal of materials science, 10(8), pp. 1381-1393. DOI: 10.1007/BF00540830. 